\title{
SABERES E EXPERIÊNCIA: FORMAÇÃO DE PROFESSORES DA REDE PÚBLICA EM ATIVIDADES EXTENSIONISTAS
}

\author{
KNOWLEDGES AND EXPERIENCE: \\ PUBLIC SCHOOL TEACHERS' \\ DEVELOPMENT THROUGH \\ EXTENSION ACTIVITIES
}

RESUMO

O objetivo do estudo foi analisar as temáticas oferecidas no Curso de Extensão Formação de Professores: um desafio contemporâneo como indicativo para a melhoria da formação de professores da rede pública. A investigação foi realizada no Centro de Pesquisa e Estudos Pedagógicos da Universidade Estadual do sudoeste da Bahia. Foram participantes 20 professores da rede pública municipal e estadual que frequentaram os três últimos cursos. Foi utilizado como instrumento um questionário semiestruturado contendo 12 questões versando sobre a contribuição do curso para a formação dos profissionais, as aprendizagens adquiridas e as mudanças oriundas a partir das experiências/vivências do curso. As temáticas foram divididas em cinco áreas, trabalhadas de forma interativa, numa perspectiva multidimensional, possibilitando aos participantes uma visão de conceitos básicos com base em atividades teórico-vivenciais: a) histórico da formação de professores no Brasil, b) prática e formação de professores, c) memórias e formação de professores, d) pesquisa em formação de professores, e) o professor multirreferencial. Dentre as aprendizagens adquiridas identificamos a valorização do conhecimento e a compreensão da relação professor e aluno; importância da continuidade da formação, melhoria da atuação profissional; reflexão da prática pedagógica; valorização docente e subjetividade do professor. Foi constatada, também, uma necessidade da aplicabilidade das temáticas na prática pedagógica dos professores. Em relação à contribuição do curso para a formação dos profissionais e as mudanças oriundas a partir das experiências/ vivências, foram relatadas a construção teórica e o amadurecimento profissional, a ampliação da visão sobre ser professor; necessidade de uma formação continuada; saber fazer docente; conhecimento sobre o cotidiano escolar. Nesse sentido, a interlocução entre saberes tem como consequências a produção do

\footnotetext{
*Professora da Universidade Estadual do Sudoeste da Bahia (UESB), BA - Brasil. E-mail: ritaksouza@hotmail.com

**Professora da Universidade Federal do Recôncavo da Bahia (UFRB), BA - Brasil. E-mail: luciagferreira@hotmail.com

***Aluna de Mestrado da Universidade Estadual do Sudoeste da Bahia (UESB), BA - Brasil. E-mail: lucimargracia@hotmail.com

****Aluna de Graduação da Universidade Estadual do Sudoeste da Bahia (UESB), BA - Brasil. E-mail: mtalmeida2015@hotmail.com
} 
conhecimento resultante do confronto com a realidade, como nos oriundos de um processo dialético teoria/prática/reflexão/prática.

Palavras-chave: contemporaneidade; formação docente; professor multirreferencial.

\begin{abstract}
:
The objective of this study was to analyze the themes offered in the Teacher Training Extension Course: a contemporary challenge as an indicative for the improvement of teacher training in the public education system. The research was carried out at the Center for Research and Pedagogical Studies of the State University of Southwest of Bahia. The participants were 20 teachers from the municipal and state public schools who attended the last three courses. A semistructured questionnaire containing 12 questions was used as an instrument to collect data on the contribution of the course to the development of those professionals, the learning acquired and the changes originated from the experiences / interactions in the course. The themes were divided into five areas interactively developed, in a multidimensional perspective, allowing the participants a vision of the basic concepts based on theoretical and experiential activities: a) history of teacher training in Brazil, b) practice and teacher training, c) memories and teacher training, d) teacher training research, e) the multireferential teacher. Among the acquired learning we identified the valorization of knowledge and the understanding of the teacher and student relationship; Importance of continuous training, improvement of professional performance; Reflection on the pedagogical practice; Teacher appreciation and teacher subjectivity. The need for the applicability of the themes in the teachers' pedagogical practice was also verified. Regarding the contribution of the course to the professionals' development and the changes derived from the experiences / interactions, the participants pointed out the theoretical construction and the professional maturation, the extension of the vision about being a teacher; the need for continuous education; the teaching know-how and the knowledge about everyday school life. In this sense, the interlocution between knowledges, has as consequences the production of knowledge resulting from the confrontation with reality, such as in a dialectical process theory / practice / reflection / practice.
\end{abstract}

Keywords: contemporaneity; teachers' development; multireferential teacher.

\title{
Introduçáo
}

A extensão, atividade articulada ao ensino e à pesquisa, consiste num processo educativo, cultural, social e científico que possibilita a relação transformadora entre a universidade e a sociedade, com base na interlocução entre saberes, que tem como consequências a produção do conhecimento resultante do confronto com a realidade, a democratização do conhecimento acadêmico e a participaçáo efetiva da comunidade na atuação da Universidade. Além de mediadora desse processo dialético de teoria/prática/ reflexão/prática, a extensão universitária é interdisciplinar, o que favorece a visão integrada de todas as dimensôes da realidade social.

O curso de Extensão Formação de Professores: um desafio da contemporaneidade, foi planejado no sentido de oferecer aos participantes a oportunidade de desenvolverem estudo e reflexáo sobre os condicionantes didáticos, sociais e políticos, assim como éticos e estéticos que configuram a formação docente e, por conseguinte, a organização da sua prática. O curso está vinculado ao Centro de Estudos e Pesquisa Pedagógica-CEPEP da Universidade Estadual do Sudoeste da Bahia e não tem a pretensão tão somente de transferir conhecimentos, mas de possibilitar a desconstruçáo/construçáo e reconstrução constante de saberes e competências necessários ao trabalho educativo.

Assim, a partir das reflexóes conjuntas, os aspectos conceituais e pressupostos teóricos abordados devem constituir-se em fundamentação básica concernente ao objetivo do curso e a possibilidade de 
inserção consciente dos participantes no contexto educacional. Os participantes são alunos dos cursos de licenciatura e professores da rede pública estadual e municipal. O curso é desenvolvido através de encontros semanais, durante os meses de março a outubro, com carga horária de 200 horas.

Nessa mesma perspectiva, este trabalho vem trazer contribuiçóes para se pensar a formação de professores a partir das exigências da contemporaneidade, tendo a extensáo também como meio de construção e desenvolvimento profissional. $\mathrm{O}$ curso enfatiza temas que buscam uma educação de qualidade, revelando a importância de açóes efetivas em prol da qualidade no ensino e a adoção de postura crítica e reflexiva de professores no seu exercício profissional.

Nunes (2000), ao historicizar as políticas públicas de formação de professores, conclui que esta permeia entre avanços legais e recuos pragmáticos. Ao longo dessa trajetória, buscaram-se melhorias na formação docente, mas surgiram formaçōes diversificadas. O investimento deve ter como foco a busca por uma transformação social. Conforme Severino (2007, p.130-131):

O investimento na formaçáo profissional do educador não pode, pois, reduzirse a uma suposta qualificação puramente técnica. Formar um educador não é repassar-lhe conhecimentos acadêmicos, pois isso não assegura a fecundidade de sua prática, que precisa subsidiar efetivas mudanças na sociedade, pela transformação das pessoas que se educam sob sua intervenção profissional. Como vimos, ela precisa ser também política, isto é, expressar sensibilidade às condiçôes histórico-sociais da existência dos sujeitos envolvidos na educação. E é sendo política que a educaçấo se tornará intrinsecamente ética. E só assim a atividade profissional do educador se tornará um efetivo investimento na construçấo e na consolidação qualitativa da cidadania.

Torna-se essencial pensar a formação de professores não só na perspectiva do currículo, como na apreensão de conteúdos a partir da incorporaçáo das experiências práticas na sua aprendizagem, no âmbito da dimensão ética e política. Nesse sentido, o currículo é mais que conteúdos, se considerarmos sua dimensão filosófica, artística, política, técnica e prática. Por isso, ao se falar de formação de professores, não se faz referência apenas a uma habilidade técnica ou ao domínio de um conjunto de informaçóes e de habilidades didáticas; falamos de uma formação humana em sua integralidade. Dessa forma, o professor precisa, dentre outras coisas, para melhor cumprir sua função social, de um maior desdobramento em termos de condiçôes pessoais das outras profissóes (SEVERINO, 2007).

A integralidade que se busca na formaçáo do professor refere-se à capacidade de promover a mudança, podendo permear várias áreas do conhecimento. Por isso, pensar no profissional docente como responsável pela boa ou má condução da educaçáo significa pensar também nas possibilidades que esse profissional tem tido para a realização de um trabalho pedagógico voltado para a mudança da sua atuação profissional. Nesse aspecto, perpassa no âmbito da profissáo de professor um paradoxo no qual "sáo vistos como profissionais pouco competentes e pouco qualificados, mas carregando a maior parte das esperanças de mudanças sociais e culturais" (LUDKE; MOREIRA; CUNHA, 1999, p. 282).

A profissão docente tem um valor social, sobre o qual deve ser enfatizada (e buscada) uma melhor formação, já que esses profissionais são essenciais no encaminhamento de 
toda vida escolar do aluno. Para Severino (2000, p.124), "a preparaçáo do educador deve realizar-se, pois, de maneira a torná-lo um profissional qualificado, plenamente consciente do significado da educação, para que possa, mediante o exercício de sua função, estender essa consciência aos educandos". Portanto, investir na formação dos professores é investir na formação do aluno e na continuidade de sua vida acadêmica após a educação básica. Entendemos que o professor é construtor de conhecimento e essa construção acaba por gerar a transformação na educação, a partir do conflito na prática e da reflexão sobre ele (SANTOS; BERNARDES, 2003). Assim, Nóvoa (1995) concebe a formação de professores como um dos componentes da mudança, que deve ter caráter permanente.

A docência se consolida como uma construçáo social e cultural. Dessa forma, este profissional se constrói a partir dos saberes e da experiência que se relaciona também ao seu desenvolvimento profissional. A profissão docente pressupóe a construção e reconstrução de saberes específicos, inerentes à profissão, oriundos da atuaçáo e da formaçáo inicial e continuada.

Nesse ínterim, a formação docente também é uma forma de expandir a identidade profissional, formada a partir de uma dimensão individual e coletiva. Assim, não se pode separar o professor da pessoa que ele representa, pois, mesmo exercendo papéis sociais diferentes, estes papéis são representados por um mesmo indivíduo. Por isso, entendemos que a identidade do indivíduo é construída a partir da cultura. Nesse sentido, esse aspecto é importante para a construção da concepçáo de mundo dos seres humanos. Assim, na escola, os professores constroem essa concepçáo de mundo a partir do contexto sóciohistórico-cultural em que vivem.

Segundo Teixeira (1996, p. 183) os "sujeitos sócio-culturais constituem-se, pois, em suas experiências vividas no mundo da vida, pelas quais se fazem a si mesmos e á história humana. Uma história-práxis de sujeitos que são, ao mesmo tempo, sua própria história”. Sendo assim, não se pode separar a pessoa e o profissional, pois a formaçáo está ligada à experiência de vida. Portanto, a história de vida do professor influencia na profissáo. Ao se formar um professor, deve-se levar em conta o contexto onde ele vive.

Nóvoa (1995, p.25) considera que "a formação não se constrói por acumulação (de cursos, de conhecimentos ou de técnicas), mas sim através de um trabalho de reflexividade crítica sobre as práticas e de (re)construção permanente de uma identidade pessoal". Formar-se não é acumular conhecimentos, mas sim adquirir saberes, aplicá-los e transformá-los em outros instrumentos de auxílio da profissão.

Há uma importância muito grande da formação inicial e continuada dos professores, haja vista que proporcionam a base e a continuidade de um processo de produção de conhecimento, o qual será aplicado ao ensino, ou seja, utilizado para formação de outras pessoas. Por isso, é necessário que os profissionais tenham, nesse percurso formativo, acesso a currículos que atendam às suas especificidades, a discussōes sobre essa temática e a momentos de reflexão sobre o contexto de atuação e suas peculiaridades.

É nesse sentido que o curso de extensão pode possibilitar ao professor uma ressignificaçáo do seu trabalho. Para o desenvolvimento das atividades desenvolvidas no curso, adotamos uma postura interdisciplinar, tomando por base não somente o discurso, mas uma postura metodológica que implicava no envolvimento, na complexidade e na compreensão, procurando articular o saber historicamente construído e religando o conhecimento, numa busca do entendimento do conteúdo exposto. Procuramos, assim, desenvolver as aulas de forma expositiva, integrada e renovadora. 
A proposiçáo das temáticas voltadas para a formaçáo dos professores buscou fornecer uma visão global e abrangente sobre os temas estudados, permitindo também ao professor uma maior vivência, que possibilitasse o desenvolvimento de uma visão crítica e mais ampla sobre a formação docente para que, com isso pudéssemos evidenciar sua aplicabilidade no mundo contemporâneo. Inicialmente, as temáticas foram divididas em seis áreas, trabalhadas de forma interativa, numa perspectiva multidimensional, possibilitando aos participantes uma visão dos conceitos básicos com base em atividades teórico-vivenciais.

Dessa forma, o objetivo deste estudo foi analisar, através de um questionário sobre as temáticas oferecidas no Curso de Extensão Formação de Professores: um desafio contemporâneo, indicativos para a melhoria da formaçáo de professores da rede pública.

\section{Método}

A investigação ocorreu no Centro de Pesquisa e Estudos Pedagógicos da Universidade Estadual do sudoeste da Bahia. Foram participantes 20 professores da rede pública municipal e estadual que frequentaram os três últimos cursos. Foi utilizado como instrumento um questionário semiestruturado contendo três eixos: 1) Ministrantes e Temas, 2) Processo Formativo, e 3) Avaliação do curso. Para este trabalho, utilizamos as questôes dos eixos 2 e 3 . As temáticas foram divididas em cinco áreas, trabalhadas de forma interativa, numa perspectiva multidimensional, possibilitando aos participantes uma visáo dos conceitos básicos para o desenvolvimento de atividades teórico-vivenciais: a) histórico da formação de professores no Brasil, b) prática e formação de professores, c) memórias e formação de professores, d) pesquisa em formação de professores, e) o professor multirreferencial. Ao final do curso, os participantes respondiam ao questionário, individualmente, como exigência das atividades desenvolvidas nesse período.

No Quadro 1 apresentamos as temáticas/conteúdos trabalhadas nos três últimos anos de realizaçấo do curso.

\section{Quadro 1. Descrição das temáticas e conteúdos trabalhados nos três últimos anos do curso de Extensão.}

\begin{tabular}{|c|c|}
\hline ANO 1 e 2 & ANO 3 \\
\hline \multicolumn{2}{|c|}{ Temáticas/Conteúdos } \\
\hline 1. Histórico da formação de professores no Brasil & 1. Histórico da formação de professores no Brasil \\
\hline $\begin{array}{l}\text { Períodos históricos: profissão docente } \\
\text { A formação docente na história } \\
\text { A feminização do magistério e gênero } \\
\text { Currículo e formação docente } \\
\text { Políticas de formação de professores }\end{array}$ & $\begin{array}{l}\text { Períodos históricos: profissão docente } \\
\text { A formação docente na história } \\
\text { A feminização do magistério e gênero } \\
\text { Currículo e formação docente } \\
\text { Políticas de formação de professores } \\
\text { O desejo de ensinar e o mal-estar docente }\end{array}$ \\
\hline 2. Prática e formação de professores & 2. Prática e formação de professores \\
\hline
\end{tabular}


conclusão

\begin{tabular}{|c|c|}
\hline ANO 1 e 2 & ANO 3 \\
\hline \multicolumn{2}{|c|}{ Temáticas/Conteúdos } \\
\hline 1. Histórico da formação de professores no Brasil & 1. Histórico da formação de professores no Brasil \\
\hline $\begin{array}{l}\text { Formação e identidade docente } \\
\text { Saberes docentes } \\
\text { Autonomia e cotidiano na formação docente } \\
\text { A subjetividade na formação de professores } \\
\text { Representaçóes Sociais } \\
\text { O desejo de ensinar e o trabalho docente } \\
\text { Ciclo da vida profissional docente }\end{array}$ & $\begin{array}{l}\text { Formação e identidade docente } \\
\text { Saberes docentes } \\
\text { Autonomia e cotidiano na formação docente } \\
\text { A subjetividade na formação de professores } \\
\text { Representaçóes Sociais } \\
\text { O desejo de ensinar e o trabalho docente } \\
\text { Ciclo da vida profissional docente }\end{array}$ \\
\hline 3. Memórias e formação de professores & 3. Memórias e formação de professores \\
\hline $\begin{array}{l}\text { Narrativas } \\
\text { (Auto)biografia } \\
\text { Histórias de vida de professores }\end{array}$ & $\begin{array}{l}\text { Narrativas } \\
\text { (Auto)biografia } \\
\text { Histórias de vida de professores }\end{array}$ \\
\hline 4. Pesquisa em Formação de professores & 4. Pesquisa em Formação de professores \\
\hline $\begin{array}{l}\text { Formação docente: indicador da qualidade de } \\
\text { ensino } \\
\text { Professor pesquisador } \\
\text { Tecnologia, EAD e formação de professores }\end{array}$ & $\begin{array}{l}\text { Relação Ensino-Pesquisa } \\
\text { Formação linguística do professor }\end{array}$ \\
\hline 5. O professor multirreferencial & 5. O professor multirreferencial \\
\hline $\begin{array}{l}\text { Multirreferencialidade e educação } \\
\text { O professor e suas especificidades (Professor de } \\
\text { Química, Física, Biologia, Educação Infantil...) } \\
\text { O professor do ensino superior }\end{array}$ & $\begin{array}{l}\text { Currículo e formação docente } \\
\text { Magistério, Gênero e Diversidade Étnica } \\
\text { Formação linguística do professor }\end{array}$ \\
\hline
\end{tabular}

Em virtude das diferentes demandas e vivências proporcionadas pelas apresentaçôes/ exposiçôes dos conteúdos, foram viabilizadas, no terceiro ano, algumas modificaçôes para a melhoria do processo formativo dos participantes. No Ano 3, foi acrescentado o conteúdo "O desejo de ensinar e o mal-estar docente" para o eixo 1 . Os eixos 4 e 5 foram os que passaram por uma maior reformulação. No eixo 4, os conteúdos foram substituídos por "Relaçẫo Ensino-Pesquisa" e "Formação linguística do professor", e no eixo 5 por "Currículo e formação docente", "Magistério, Gênero e Diversidade Étnica" e "Formação linguística do professor".

As respostas dos questionários foram analisadas através da Análise de Conteúdo (BARDIN, 2006). Na sequência, foram identificadas as categorias que contemplariam o foco central da investigação: processo formativo e contribuição do curso para a formação dos profissionais, aprendizagens adquiridas e mudanças oriundas a partir das experiências/ vivências pelo curso.

\section{Resultados}

Dentre as categorias organizadas através do questionário, destacamos: a) contribuição do curso para a formação dos profissionais, b) aprendizagens adquiridas, e c) mudanças oriundas a partir das experiências/vivências pelo curso. Na sequência, as falas dos participantes que constituíram as categorias foram, entáo, organizadas em tópicos. 
Em relação à categoria contribuição do curso para a formação dos profissionais, foram relacionados os tópicos: importância de uma construção teórica e amadurecimento profissional; a ampliaçáo da visão sobre ser professor; necessidade de uma formaçáo continuada; conhecimento sobre o cotidiano escolar. No tópico que trata sobre a importância de uma construçáo teórica e amadurecimento profissional, destacamos que os professores a concebem como uma condição essencial para o desenvolvimento profissional.

Marcelo Garcia (2009, p. 7) denomina o desenvolvimento profissional como:

[...] um processo individual e colectivo que se deve concretizar no local de trabalho do docente: a escola; e que contribui para o desenvolvimento das suas competências profissionais, através de experiências de índole diferente, tanto formais como informais. O conceito de desenvolvimento profissional tem vindo a modificar-se durante a última década, sendo essa mudança motivada pela evolução da compreensão de como se produzem os processos de aprender a ensinar. Nos últimos tempos, tem-se vindo a considerar o desenvolvimento profissional como um processo a longo prazo, no qual se integram diferentes tipos de oportunidades e experiências, planificadas sistematicamente para promover o crescimento e desenvolvimento do docente.

Segundo o autor, o processo de construção profissional do docente pode ser influenciado pela:

[...] escola, pelas reformas e contextos políticos, e que integra o compromisso pessoal, a disponibilidade para aprender a ensinar, as crenças, os valores, o conhecimento sobre as matérias que ensinam e como as ensinam, as experiências passadas, assim como a própria vulnerabilidade profissional. As identidades profissionais configuram um complexo emaranhado de histórias, conhecimentos, processos e rituais (MARCELO GARCIA, 2009, p. 7).

Nesse sentido, podemos considerar que essa diversidade de fatores que influenciam o desenvolvimento profissional pode ser identificada nos dados dessa investigaçáo. Percebemos uma articulação e integração dos tópicos construídos, não somente aos relacionados à contribuição do curso para a formação dos profissionais, como também nos presentes nas aprendizagens adquiridas e nas mudanças oriundas a partir das experiências/ vivências pelo curso.

O professor é uma pessoa e parte dessa pessoa é o professor (NÓVOA, 1992). Marcelo Garcia (2009) corrobora com isso ao afirmar que o desenvolvimento profissional é um processo contínuo e que o professor se desenvolve profissionalmente continuamente. O professor tem uma representação e não podemos separá-lo dela, mas entendê-lo, juntamente com o seu processo de desenvolvimento, fato demonstrado em diversas pesquisas (FERREIRA, 2010, 2014; FERREIRA, BEZERRA, 2015; D’ÁVILA, 2007; VEIGA, AMARAL, 2005).

Os aspectos caracterizados acima interferem diretamente na condição docente. Isto está representado no tópico sobre a necessidade de uma amplitude sobre o ser professor que perpassa pela compreensão de que a docência tem suas características próprias (naturais), mas vivenciada por todos de diferentes maneiras. Sáo os sentidos e significados construídos durante o desenvolvimento profissional do professor. Para Arroyo (2007), é estabelecido um vínculo entre o contexto social, histórico, político, econômico e cultural da educação com o processo formativo e a atuação dos professores. Conforme 
Tardif (2002), no cotidiano da atuação docente, estes fazem uso de conhecimentos que se articulam às suas vivências e saberes, o que recai sobre o conhecimento do cotidiano escolar.

É essa reflexão dos professores sobre a sua própria prática que contribui para que eles produzam conhecimentos teóricos e práticos oriundos de suas experiências (MARCELO GARCIA, 1999). Segundo o autor, esses momentos podem gerar também uma formação docente, caracterizando um processo de desenvolvimento profissional. Considera, ainda, que:

[...] conceber a formação de professores, tal como temos feito nesse trabalho, como um "processo contínuo, sistemático e organizado" significa entender que a formação de professores abarca toda a carreira docente. Falar da carreira docente não é mais do que reconhecer que os professores, do ponto de vista do "aprender a ensinar", passam por diferentes etapas (pré-formação, formação inicial, iniciação e formação permanente) (MARCELO GARCIA, 1999, p. 112).

Nessa perspectiva, os professores aprendem, no percurso profissional, que a formação contínua favorece a aprendizagem da docência: período de formaçáo e de atuaçáo. É dessa forma que a formaçáo passa a ser parte essencial ao desenvolvimento profissional e à reflexáo sobre a vivência docente. $\mathrm{O}$ desenvolvimento profissional deve considerar o significado de ser profissional e como os professores devem exercer sua funçấo com dignidade e autonomia. A respeito da profissão docente, Marcelo Garcia e Vaillant (2009) apontam que deve considerar a experiência e a cultura profissionais como importantes aspectos da profissão; considerando que as experiências individuais podem tornar-se coletivas (FERREIRA, 2014).

Através das temáticas propostas e sedimentadas pela compreensão dos participantes, entendemos que a formação do professor também produz sua subjetividade, que se refere à compreensão que ele tem do significado de sua prática docente, a partir de sua formação. Suas açôes incorporam reflexôes sobre o fazer pedagógico, o que, segundo Cunha (2005), influencia na constituição do ser professor, perpassada pelo sentimento que ele manifesta nesse fazer pedagógico.

A identidade do professor, portanto, está relacionada com a própria identidade da profissáo docente, construída dentro de um processo histórico-cultural e formada na relaçáo com outros sujeitos, gerando novas identidades em constante processo de transformação (NÓVOA, 1995). Assim, a "maneira como cada um de nós ensina está diretamente dependente daquilo que somos como pessoa quando exercemos o ensino" (NÓVOA, 1995, p. 17).

Isso foi compreendido a partir dos tópicos identificados na categoria aprendizagens adquiridas: compreensáo sobre a relaçáo professor e aluno; saber fazer docente; reflexấo da prática pedagógica; valorizaçáo docente; subjetividade do professor. Percebemos, a partir desses tópicos, uma articulação entre o ser professor e sua atuação pedagógica.

A transformação no olhar do professor requer uma formação continuada que permita a construção de experiências inovadoras, provocando mudanças na escola, no projeto pedagógico e no próprio docente. Logo, o investimento na pessoa do professor e na sua profissão deve buscar uma valorização do seu desenvolvimento pessoal-profissional. 
Essa mudança deve, no entanto, privilegiar as condiçóes histórico-culturais desse desenvolvimento, pois se entende que a subjetividade é formada por sujeitos concretos que, apesar da singularidade, são constituídos histórica e culturalmente.

Essa constituiçáo da subjetividade do professor, principalmente em uma perspectiva histórico-cultural, ganha espaço nas discussóes sobre o contexto escolar e o ser professor (CUNHA, 2000; FONTANA, 2000).

Considera-se, nesse sentido, que a valorização do processo pedagógico é um fator importante para o desenvolvimento do aprender, como identificado no tópico compreensão sobre a relação professor e aluno. Convém ressaltar que Arroyo (2000) faz uma reflexáo sobre o fato de que o trabalho e a ação educativa dada na sala de aula e no convívio entre professores e alunos trazem, ainda, as marcas da especificidade da ação educativa. É através da sua prática educativa que o professor também produz a si próprio, mediante as relaçóes estabelecidas, principalmente, com os alunos.

Nesse processo de construção da subjetividade, uma problemática abordada pelos participantes foi sobre o adoecimento profissional. Apesar de ser um tema recorrente na formaçáo docente, torna-se atual, em virtude do alto índice de professores que vivenciam esse mal. A Síndrome de Burnout, que afeta profissóes vulneráveis como as da área de educação, se configura como "um tipo de estresse ocupacional que acomete profissionais envolvidos com qualquer tipo de cuidado em uma relação de atenção direta, contínua e altamente emocional". As consequências da Síndrome de Burnout nos professores têm manifestação tanto no campo pessoal-profissional, como na organização escolar, na relação com os alunos (CARLOTTO, 2002, p. 27).

$\mathrm{Na}$ categoria mudanças oriundas a partir das experiências/vivências pelo curso, destacamos os tópicos: valorizaçáo do conhecimento; importância da continuidade da formaçáo; melhoria da atuaçáo profissional; necessidade da aplicabilidade das temáticas na prática pedagógica dos professores.

Ressaltamos a importância da formaçáo continuada para a melhoria da atuaçáo profissional, pois sabemos que, a partir da década de 1990, se tornou referência na busca de um novo perfil profissional do professor. Contudo, no Brasil, esse tipo de formação emerge de diferentes concepções de educação e sociedade presentes em nossa realidade (SILVA; ARAÚJO, 2005).

Bernardo (2004), ao se referir às políticas públicas, relata que a formação de professores tem sido uma preocupação presente nas reformas e nas investigaçóes (publicadas). O autor destaca que "nessas dimensóes, a formaçáo continuada aparece associada ao processo de melhoria das práticas pedagógicas desenvolvidas pelos professores em sua rotina de trabalho e em seu cotidiano escolar" (BERNARDO, 2004, p.1). Nesse sentido, várias pesquisas sobre professores têm apontado a "insuficiência da formaçáo inicial para o desenvolvimento profissional do professor, mesmo a que é realizada em nível superior, seja para a necessidade de se levar em conta o saber do professor, seja para a escola como lócus de formação docente" (p. 1). Assim, considera-se que nenhuma formação inicial é realmente suficiente para o desenvolvimento profissional, e a formaçáo continuada passa a ser buscada com o intuito de valorização da prática do professor e para a aquisiçáo de conhecimentos advindos de pesquisas acadêmicas, procurando sempre a articulação teoria/prática. 
Os participantes perceberam, através do curso, a necessidade de aplicaçáo dos conteúdos nas suas práticas. Esse exercício reflexivo é indicativo de que a apreensão do conhecimento construído pelo curso de extensão pode promover uma transformação não somente da atuação do professor como também de seu desenvolvimento profissional e pessoal.

Por fim, essas discussóes sobre o professor e a/na contemporaneidade possibilitaram reflexôes que foram indicativas da construção de sentidos e significados sobre a profissão docente e a sua formaçáo que repercutirão sobre a atitude frente à prática educativa. Além do mais, essas reflexóes ajudarão a pensar e construir um projeto profissional visando contribuir para uma ação docente mais qualificada na escola pública.

\section{Conclusóes}

O curso de extensão atuou como uma atividade de formação continuada e envolveu temas diversos que foram discutidos e apreendidos pelos participantes. Consideramos que este tipo de formaçáo deve atender a todas as licenciaturas, pois, na sociedade em que vivemos, formar professores para viver na contemporaneidade é formar para a mudança e também para a incerteza.

Ressaltamos a necessidade de criar açóes extensionistas que proporcionem impactos na postura de professores e futuros professores, ou seja, na necessidade de investimentos por parte das instituiçôes educacionais para a articulação do ensino, pesquisa e extensão, pois a realizaçáo de cursos como este é capaz de proporcionar reflexôes sobre a prática docente. Nesse sentido, a interlocução entre saberes tem como consequências a produção do conhecimento, resultante do confronto com a realidade, como nos oriundos de um processo dialético teoria/prática/reflexão/prática.

\section{Referências}

ARROYO, Miguel. Ofício de Mestre: Imagens e Auto-imagens. Petrópolis: Vozes, 2000.

BARDIN, L. Análise de conteúdo (REGO, L. de A.; PINHEIRO, A. Trads.). Lisboa: Edições 70. 2006. (Obra original publicada em 1977).

BERNADO, E. S. Um olhar sobre a formação continuada de professores: escolas organizadas no regime de ensino em ciclo(s). In: REUNIÃO ANUAL DA ANPED: Sociedade, democracia e educação: qual universidade?, 27., 2004. Anais... Caxambu/MG: Anped, 2004. Disponível em: www.anped.org.br/reunioes/27/gt08/t083.pdf. Acesso em: 23/09/2009.

CARLOTTO, M. A. A Síndrome de Burnout e o trabalho docente. Psicologia em Estudo, Maringá, v. 7, n. 1, p. 21-29, jan./jun. 2002.

CUNHA, M. D. da. Subjetividade e constituição de professores. In: GONZALEZ REY, F. (Org.). Subjetividade, complexidade e pesquisa em Psicologia. São Paulo: Thomson Learning, 2005. p. 191-213. 
Constituição de professores no espaço-tempo da sala de aula. Tese (Doutorado em Psicologia Educacional) - Universidade Estadual de Campinas, Faculdade de Educação, Campinas, São Paulo, 2000.

D'ÁVILA, C. Universidade e Formação de professores: qual o peso da formação inicial na construção da identidade profissional docente? In: NASCIMENTO, A. D.; HETKOWSKI, T. Memória e formação de professores. Salvador/BA: EDUFBA, 2007, p. 219-240.

FERREIRA, L. G. Professoras da zona rural: formação, identidade, saberes e práticas. Dissertação (Mestrado em Educação e Contemporaneidade) - Universidade do Estado da Bahia, Salvador/BA, 2010.

Professores da zona rural em início de carreira: narrativas de si e desenvolvimento profissional. Tese (Doutorado em Educação) - Universidade Federal de São Carlos, São Carlos/SP, 2014.

FERREIRA, L. G.; BEZERRA, P. O. O professor do ensino superior e sua formação: uma discussão necessária. Revista de Ciências da Educação. Americana, Ano XVII, v. 1, n. 32, p. 5-28, jan./jun. 2015,

FONTANA, R. Trabalho e subjetividade. Nos rituais da iniciação, a constituição do ser professora. Cadernos Cedes, Ano XX, n. 50, p. 103-119, abr./2000.

LUDKE, M.; MOREIRA, A.F.B.; CUNHA, M.I. da. Repercussões de tendências internacionais sobre a formação de nossos professores. Revista Educação e Sociedade. Ano XX, n. 68, dez./1999.

MARCELO GARCIA, C. Formação de professores: para uma mudança educativa. Porto, PT: Porto Editora, 1999.

. Desenvolvimento Profissional: passado e futuro. Sísifo - Revista das Ciências da Educação, n. 8, p. 7-22, jan./abr. 2009.

MARCELO GARCIA, C.; VAILLANT, D. Desarrollo professional docente: como se aprende a enseñar? Madrid: Narcea, S.A. de Ediciones, 2009.

NÓVOA, A. (Coord.) Os professores e sua formação. Lisboa, Portugal: Dom Quixote, 1995.

NUNES, C. Formação docente no Brasil: entre avanços legais e recuos pragmáticos. Teias Revista da Faculdade de Educação da UERJ, Rio de Janeiro, v. 1, n.1, p. 16-30, 2000.

SANTOS, S. M.; BERNARDES, V. A. M. História de formação de professores. Cadernos da Fucamp, Patos de Minas, v. 2, p. 59-77, 2003.

SEVERINO, A.J. Formação docente: conhecimento científico e saberes dos professores. Ariús, Campina Grande, v. 13, n. 2, p. 121-132, jul./dez. 2007.

SILVA, E. M. A.; ARAÚJO, C. M. Reflexão em Paulo Freire: uma contribuição para a formação continuada de professores. In: COLÓQUIO INTERNACIONAL PAULO FREIRE, 5., 2005. Anais... Recife, 2005. p. 1-8. 
TARDIF, M. Saberes docentes e formação profissional. Petrópolis: Vozes, 2002.

TEIXEIRA, I. C. Os professores como sujeitos sócio-culturais. In: DAYRELL, J. (Org.). Múltiplos olhares sobre a educação e a cultura. Belo Horizonte: Ed. UFMG, 1996. p.179-194.

VEIGA, I. P. A.; AMARAL, A. L. (Orgs.). Formação de professores: políticas e debates. São Paulo, SP: Papirus, 2002, p. 47-61. 